\title{
Post-donation satisfaction in kidney transplantation: a survey of living donors in Japan
}

Sayaka Kobayashi ${ }^{1,2 \dagger}{ }^{\dagger}$, Rie Akaho ${ }^{1 \dagger}$, Kazuya Omoto ${ }^{3,4}$, Hiroki Shirakawa ${ }^{3,5}$, Tomokazu Shimizu ${ }^{3,4}$, Hideki Ishida ${ }^{3,6}$, Kazunari Tanabe ${ }^{3}$ and Katsuji Nishimura ${ }^{1 *}$

\begin{abstract}
Background: No studies using a valid, standardized method to measure post-donation satisfaction levels among living kidney donors (LKDs) have been published.

Methods: Donor satisfaction levels were measured using the Japanese version of the Client Satisfaction Questionnaire-8 (CSQ-8), a validated, self-report questionnaire. To identify factors related to post-donation satisfaction levels, we compared donors' sociodemographic and psychological characteristics and health-related quality of life (HRQoL), using the Short Form-36 Health Survey (SF-36), as well as recipients' clinical characteristics and SF-36 scores between donors with and without low satisfaction. In addition, donors' perceptions of the donation results and transplant procedure were assessed using measures that we developed.

Results: The mean (standard deviation [SD]) CSQ-8 score for the 195 participants was 26.9 (3.4). Twenty-nine (14.9\%) respondents with total scores < 1 SD below the mean CSQ-8 score were placed into the low satisfaction group. Multiple logistic regression analysis demonstrated that lower perceptions of receiving adequate information prior to transplantation (odds ratio $[\mathrm{OR}]=0.17 ; 95 \%$ confidence interval $[\mathrm{Cl}]=0.079-0.379 ; p<0.001$ ), lower optimism according to the Life Orientation Test $(\mathrm{OR}=1.24 ; 95 \% \mathrm{Cl}=1.045-1.470 ; p=0.014)$, and increased serum creatinine levels in the paired recipient $(\mathrm{OR}=0.05 ; 95 \% \mathrm{Cl}=0.250-1.011 ; p=0.054)$ independently increased the odds of having less satisfaction with donation.
\end{abstract}

Conclusions: Our findings suggest that careful pre-donation education and more detailed informed consent may be needed, especially in LKDs with low constitutional optimism.

Keywords: Post-donation satisfaction, Living kidney donors

\section{Background}

Healthy living kidney donors (LKDs) do not reap medical benefits from donation but stand to gain a sense of satisfaction through the contribution that they make to recovery of the recipient's health. Therefore, postdonation satisfaction levels could be considered an important outcome for the donor.

Many health-related quality of life (HRQoL) studies have been conducted on post-donation outcomes for the

\footnotetext{
* Correspondence: nishimura.katsuji@twmu.ac.jp

†Sayaka Kobayashi and Rie Akaho contributed equally to this work.

${ }^{1}$ Department of Psychiatry, Tokyo Women's Medical University, School of

Medicine, Tokyo, Japan

Full list of author information is available at the end of the article
}

donor. According to these studies, $93-97 \%$ of donors have said, "I would donate again, given another chance" [1-7]. These findings also mean that $3-7 \%$ of donors do not share this opinion, thus suggesting that some donors' satisfaction levels are low. For example, in a large cross-sectional study of 1414 LKDs in Norway, $80.7 \%$ of donors answered "definitely", 13.9\% "probably", $2.3 \%$ "don't know", $1.8 \%$ "probably not", and $1.3 \%$ answered "definitely not" when asked whether they would donate again [6]. This question has primarily been used as a measure of post-donation satisfaction among LKDs in several studies. However, this question may have less to do with the decision-making process than it does with donors' satisfaction with the recipient's outcome [8]. A

(c) The Author(s). 2019 Open Access This article is distributed under the terms of the Creative Commons Attribution 4.0 International License (http://creativecommons.org/licenses/by/4.0/), which permits unrestricted use, distribution, and reproduction in any medium, provided you give appropriate credit to the original author(s) and the source, provide a link to the Creative Commons license, and indicate if changes were made. The Creative Commons Public Domain Dedication waiver (http://creativecommons.org/publicdomain/zero/1.0/) applies to the data made available in this article, unless otherwise stated. 
recent study using exploratory factor analyses demonstrated that donors' satisfaction was composed of three factors (unmet donor expectations about donation, interference of donation with daily activities, and pain and discomfort), which were not differentiated in the abovementioned single question [9].

To our knowledge, there are no published studies that have used a valid, standardized method to measure postdonation satisfaction levels. Here, we used the Japanese version of the Client Satisfaction Questionnaire-8 (CSQ8) $[10,11]$, a standardized measure for global client/patient satisfaction with health services and clinical care.

A systemic review of the psychosocial health of LKDs demonstrated that a small proportion of LKDs had adverse psychosocial outcomes, such as decreased psychological well-being (e.g., depression) and a decrease in HRQoL [12], which may lead to post-donation dissatisfaction. Optimism may positively affect psychological [13] and physical [14] aspects among LKDs. Furthermore, the decision-making process surrounding whether to donate may be crucial for post-donation psychosocial outcomes in LKDs [15]. In Japan, living organ donors are, in principle, limited to family members (blood relatives within six degrees of kinship or relatives by marriage within three degrees of kinship), which may affect decision-making based on Asian attitudes regarding family relationships [16, 17]. Lower-quality relationships between recipients and family members or feelings of unattractiveness that occur after donation may also result in donor dissatisfaction [12].
In this study, we followed a new approach to evaluate post-donation satisfaction using the CSQ-8, a standardized measure. We aimed to clarify the factors associated with post-donation satisfaction among LKDs, primarily family members.

\section{Methods \\ Participant recruitment}

This study was conducted as part of a long-term HRQOL study of living, related kidney recipients and donors at our transplant center. We consecutively recruited 443 living, related kidney post-transplant recipients, who visited our follow-up clinic between 1 February and 31 March, 2011 to participate in our study. Of the 443 recipients, 90 declined and 353 agreed to participate. At the same time, we asked these recipients if we could request their paired donor to participate in our study. If they agreed, questionnaire surveys were administered to recipients or sent by mail to the paired donors. The paired donor of two recipients had died, and six recipients said that they could not contact their donors. Finally, questionnaire surveys were mailed or administered directly to a total 345 donors. Of these 345 donors, 100 did not respond, 22 provided incomplete surveys, and 28 surveys lacked medical information. Finally, 195 donors were included in the analysis (Fig. 1). This study was approved by the human ethics review board of Tokyo Women's Medical University, and all participants signed a consent form.

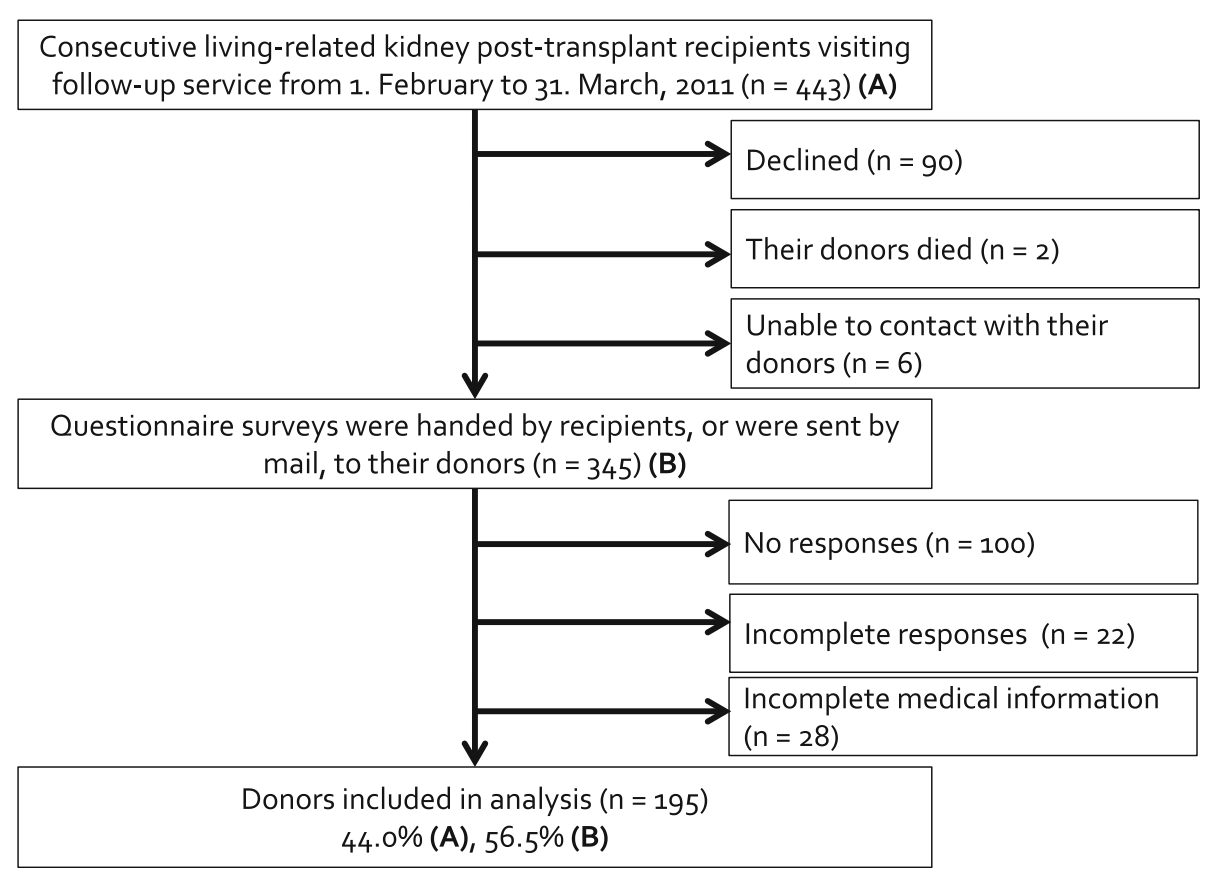

Fig. 1 Flow diagram of participant recruitment 


\section{Assessment of post-donation satisfaction}

All donors received a survey packet consisting of the following self-reporting tools. Donor satisfaction levels were measured using the Japanese version of the CSQ-8 $[10,11]$. The CSQ-8 is a validated, self-report questionnaire for measuring satisfaction with a wide range of services and has been tested in numerous studies among diverse client/ patient samples. The most extensive use of the CSQ-8 scale has been within mental health treatment, primary medical care, and a wide range of human service settings [18-20]. The CSQ-8 includes questions on the following eight topics (abbreviated), with response options provided on a 4-point Likert scale: quality of service received, received the desired service, respondents' needs were met, would recommend to a friend, satisfied with the amount of help, deal more effectively with problems, satisfied with service, and would come back for service. The total possible score ranges from 8 to 32. Higher scores indicate greater satisfaction. To fit the context of LKDs, we added a note that "service" refers to "the whole process of living kidney transplantation, including your donation".

To identify LKDs with low post-donation satisfaction, we classified the total CSQ-8 scores of participants into the following two groups: (a) low satisfaction group: $<1$ standard deviation (SD) lower than the mean CSQ-8 score, and (b) non-low satisfaction group: $\geq 1$ SD lower than the mean CSQ-8 score. Because the abovementioned response to the question "I would donate again, given another chance" could possibly underestimate post-donation dissatisfaction [9], we chose $1 \mathrm{SD}$ below the mean CSQ-8 score as the cut-off point for low satisfaction.

\section{Assessment of health-related and psychosocial variables} The Short Form-36 Health Survey (SF-36) Japanese edition [21], a standardized self-reported questionnaire, was used to assess health-related quality of life (HRQoL). We used the Japanese version of the Zung Self-Rating Depression Scale (SDS) [22], a validated, self-reported, 20questioninstrument, to assess psychological and somatic symptoms of depression. We used the Japanese version of the Life Orientation Test (LOT) [23], a valid, 12-item, 5point scale instrument to assess individual differences in general optimism and pessimism.

Furthermore, using eight author-developed questions, we collected demographic information, including age at the time of survey, sex, time since donation, relationship to the recipient, total years of education, marital status, cohabitation status, and participants' employment status.

\section{Donors' perceptions of donation results and transplant procedure}

We also assessed donors' perception of the results of donation and transplantation procedure using a 13-item scale that we developed in other study (see Additional file 1) [24]. Items on this scale were extracted in a qualitative study of potential LKDs on the factors influencing decisionmaking when considering donation. Using data from 228 LKDs, these items were divided into 5 factors including 13 items, in factor analyses. These factors were: (1) good relationship with and support from family members; (2) adequate information prior to transplantation; (3) recipient's recovery; (4) recipient's gratitude toward the donor; (5) increase in self-esteem/self-worth after donation. The reliability of each factor has been confirmed, with good internal consistency.

\section{Assessment of paired recipients}

Paired recipients also received a survey packet that included the CSQ-8, SF-36, SDS, and LOT. As an indicator of post-transplant physical condition, serum creatinine levels were collected from recipients at the time of the survey.

As mentioned, we classified the total CSQ-8 scores of participants into two groups according to satisfaction level, using a cut-off point 1 SD below the mean, which were used as dependent variables in the analysis. For the univariate analyses, a two-tailed test was used to identify differences between groups for continuous variables, and a chi-square test was used for categorical variables. To identify independent risk factors among donors with low satisfaction, multiple logistic regression analysis was performed, with forward stepwise variable selection. Variables from the univariate analyses with $p<0.1$ were entered into a forward logistic regression model. Regression coefficients were used to calculate the odds ratio (OR) and 95\% confidence interval (CI) of the OR. In all statistical analyses, $p$ values $<0.05$ were considered statistically significant. We performed all analyses using IBM SPSS Statistics, version 20 (IBM Corp., Armonk, NY, USA).

\section{Results \\ Post-donation satisfaction levels}

The mean (SD) CSQ-8 score for the 195 participants was 26.9 (3.4). Twenty-nine (14.9\%) participants were categorized into the low satisfaction group (Fig. 2). Distributions of each subscale score of the CSQ-8 are shown in Fig. 3. On the topic "would come back for service", 14 respondents (7.2\%) did not agree: 11 answered "No, I don't think so" and 3 answered "No, definitely not".

\section{Factors related to satisfaction levels}

To identify factors related to post-donation satisfaction levels, we first used univariate analysis to compare donors' sociodemographic, psychological, and health characteristics, and post-donation perceptions, as well as recipients' clinical, psychological, and health characteristics between 


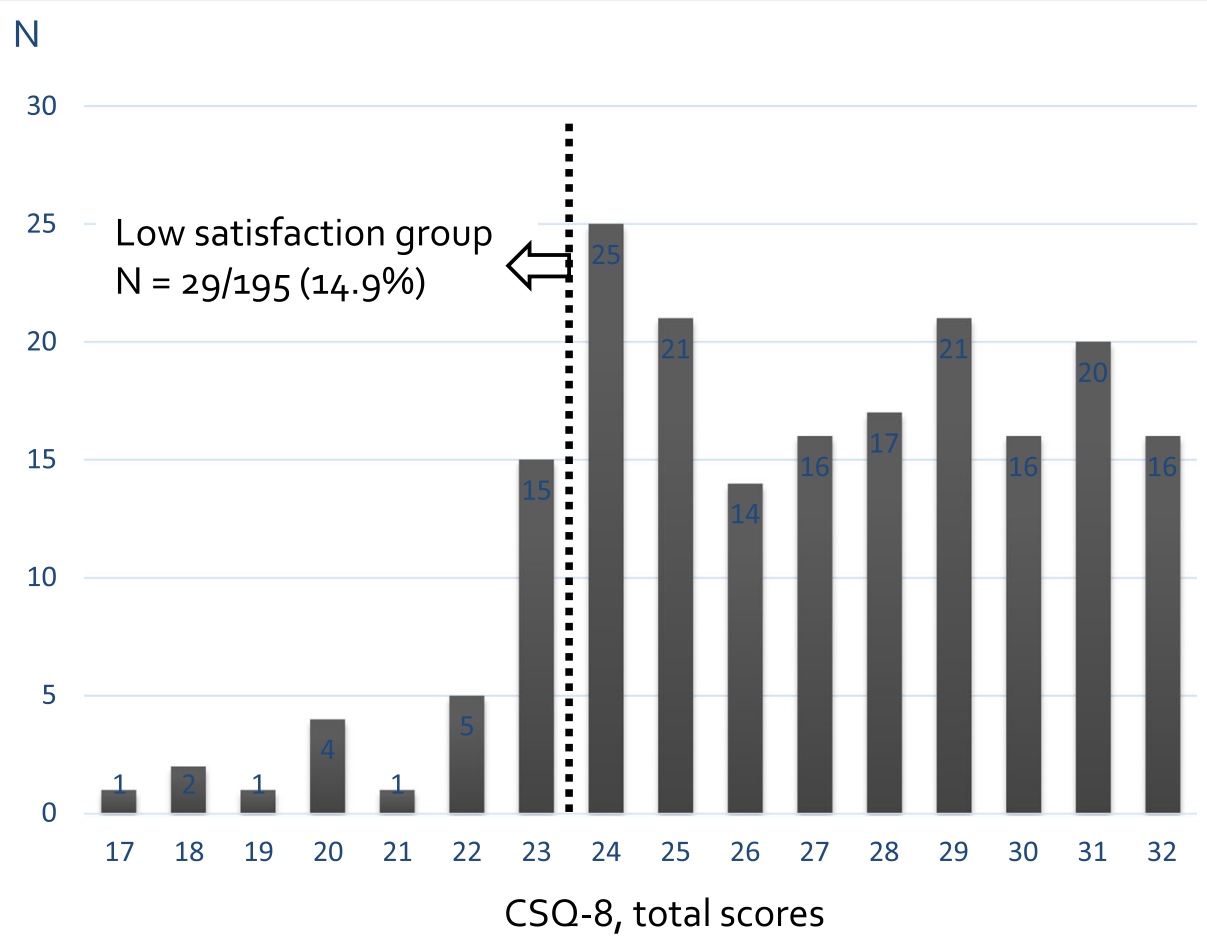

Fig. 2 Distribution of Client Satisfaction Questionnaire-8 scores. Dashed line indicates 1 standard deviation below the mean score

the groups with and without low levels of satisfaction (Table 1). Scores for post-donation perceptions of "receiving adequate information prior to transplant" $(p=0.001)$ and "increase in self-esteem/self-worth after donation" $(p=0.038)$ were significantly higher in the low satisfaction group than in the non-low satisfaction group (lower score indicates better perception). The Self-Rating Depression Scale score of donors was higher $(p=0.01)$, and the optimism score on the LOT of donors was significantly lower $(p=0.01)$ in the low satisfaction group than in the nonlow satisfaction group.

In the second step, we performed multiple logistic regression analysis using the forward stepwise selection method and six data sets, including serum creatinine level as well as CSQ-8 score of recipients, in addition to the above-mentioned variables that were significant in univariate analysis. Of the six variables, lower perceptions of "receiving adequate information prior to transplant"

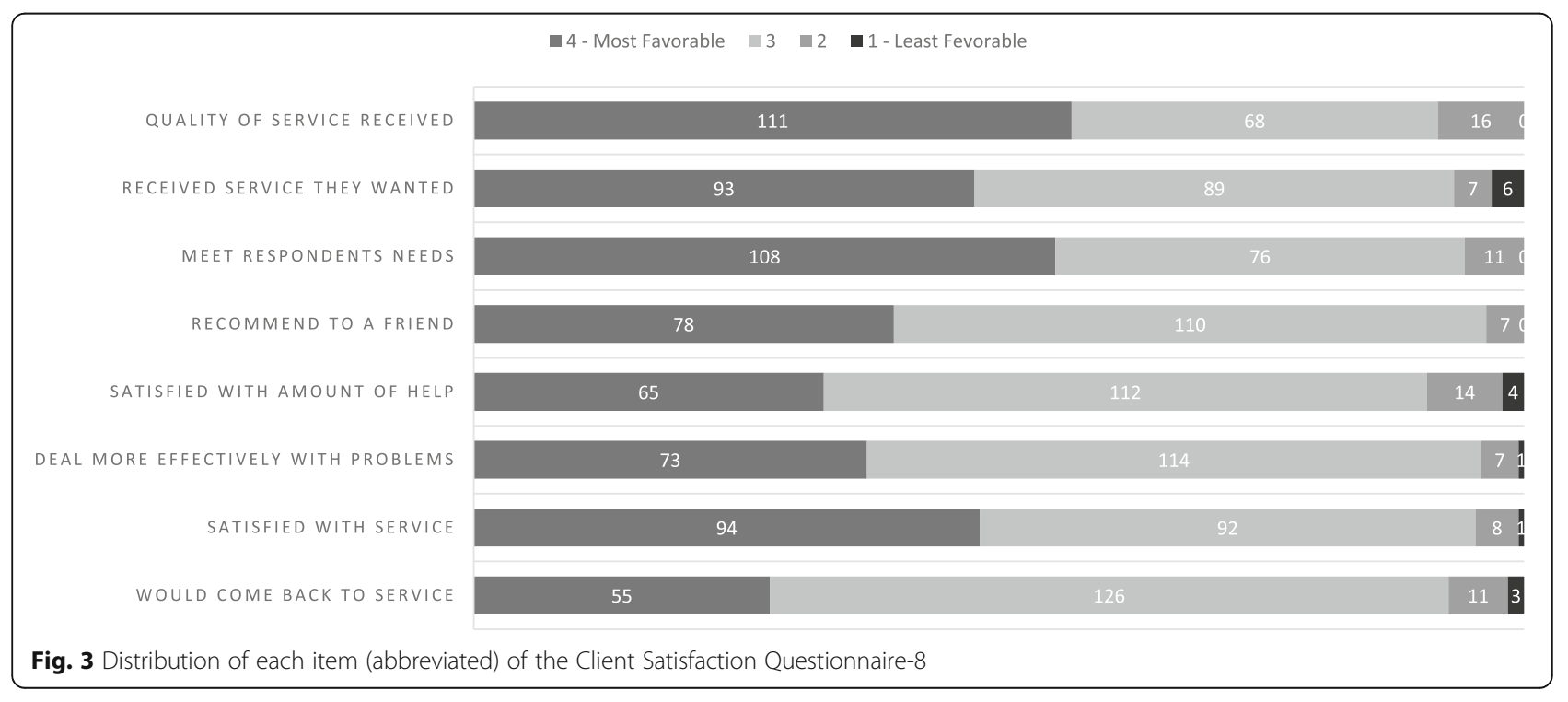


Table 1 Relationship between satisfaction levels and sociodemographic, psychological, and health characteristics

\begin{tabular}{|c|c|c|c|}
\hline & \multicolumn{2}{|c|}{ Donor satisfaction levels } & \multirow[t]{2}{*}{$p$} \\
\hline & Low $(n=29)$ & Non-low $(n=166)$ & \\
\hline \multicolumn{4}{|l|}{ Donor variables } \\
\hline Age, years (mean $\pm S D$ ) & $61.5 \pm 10.7$ & $61.2 \pm 9.6$ & 0.887 \\
\hline Female sex & $22(75.9 \%)$ & \multirow{2}{*}{$\begin{array}{l}113(68.1 \%) \\
58.2(1.0-833.3)\end{array}$} & 0.402 \\
\hline Time since donation, months & $57.3(3.8-205.3)$ & & 0.935 \\
\hline Relationship with recipient & & & 0.949 \\
\hline Parent & $15(51.7 \%)$ & $88(53.0 \%)$ & \\
\hline Child & $0(0 \%)$ & $2(1.2 \%)$ & \\
\hline Sibling & $3(10.3 \%)$ & $17(10.2 \%)$ & \\
\hline Spouse & $9(31.0 \%)$ & $56(33.7 \%)$ & \\
\hline Education, $\leq 12$ years & $15(51.7 \%)$ & $88(53.0 \%)$ & 0.773 \\
\hline Married, current & $21(72.4 \%)$ & $138(83.1 \%)$ & 0.254 \\
\hline \multicolumn{4}{|l|}{ Cohabitation, current } \\
\hline With family & $24(82.8 \%)$ & $147(88.6 \%)$ & 0.796 \\
\hline With recipient & $17(58.6 \%)$ & $86(51.8 \%)$ & 0.340 \\
\hline With recipient prior to transplantation & $18(62.1 \%)$ & $104(62.7 \%)$ & 0.899 \\
\hline Not employed, current & $5(17.2 \%)$ & $28(16.9 \%)$ & 0.876 \\
\hline \multicolumn{4}{|l|}{ Perception of donation results and transplant procedure } \\
\hline Good relationship with and support from family members & $1.40 \pm 0.49$ & $1.28 \pm 0.53$ & 0.279 \\
\hline Adequate information prior to transplant & $1.97 \pm 0.78$ & $1.41 \pm 0.43$ & $0.001^{\mathrm{a}}$ \\
\hline Recipients' recovery & $1.41 \pm 0.50$ & $1.43 \pm 0.61$ & 0.908 \\
\hline Recipient's gratefulness to the donor & $1.41 \pm 0.54$ & $1.26 \pm 0.47$ & 0.109 \\
\hline Increase in self-esteem/self-worth through donation & $1.59 \pm 0.64$ & $1.36 \pm 0.54$ & $0.038^{\mathrm{a}}$ \\
\hline Self-Rating Depression Scale & $39.1 \pm 9.1$ & $35.3 \pm 6.7$ & $0.01^{\mathrm{a}}$ \\
\hline \multicolumn{4}{|l|}{ Life Orientation Test } \\
\hline Optimism & $13.7 \pm 2.7$ & $15.1 \pm 2.6$ & $0.01^{\mathrm{a}}$ \\
\hline Pessimism & $11.2 \pm 3.1$ & $11.2 \pm 2.7$ & 0.970 \\
\hline \multicolumn{4}{|l|}{ SF-36 } \\
\hline Physical function & $87.8 \pm 22.1$ & $92.1 \pm 12.1$ & 0.122 \\
\hline Role - physical & $83.8 \pm 27.1$ & $89.0 \pm 20.7$ & 0.24 \\
\hline Bodily pain & $73.7 \pm 34.1$ & $77.5 \pm 30.5$ & 0.58 \\
\hline General health & $73.5 \pm 17.9$ & $71.6 \pm 18.6$ & 0.605 \\
\hline Vitality & $68.5 \pm 18.0$ & $71.8 \pm 21.0$ & 0.383 \\
\hline Social function & $82.3 \pm 24.4$ & $84.9 \pm 23.5$ & 0.607 \\
\hline Role - emotional & $89.4 \pm 20.8$ & $89.5 \pm 20.1$ & 0.973 \\
\hline Mental health & $79.3 \pm 13.7$ & $79.4 \pm 16.9$ & 0.976 \\
\hline \multicolumn{4}{|l|}{ Recipient variables } \\
\hline Age at transplantation, years & $41.9 \pm 13.6$ & $41.8 \pm 13.9$ & 0.966 \\
\hline Dialysis duration before transplant, months & $67.8 \pm 68.9$ & $53.5 \pm 52.2$ & 0.287 \\
\hline Serum creatinine level, current, mg/dL & $1.5 \pm 1.2$ & $1.3 \pm 0.4$ & 0.095 \\
\hline CSQ-8 & $28.1 \pm 3.0$ & $29.2 \pm 2.7$ & 0.072 \\
\hline Self-Rating Depression Scale & $36.3 \pm 7.5$ & $36.5 \pm 7.3$ & 0.873 \\
\hline \multicolumn{4}{|l|}{ Life Orientation Test } \\
\hline Optimism & $12.8 \pm 2.8$ & $13.4 \pm 3.4$ & 0.333 \\
\hline
\end{tabular}


Table 1 Relationship between satisfaction levels and sociodemographic, psychological, and health characteristics (Continued)

\begin{tabular}{llll}
\hline & Donor satisfaction levels & & \\
\cline { 2 - 3 } & Low $(n=29)$ & Non-low $(n=166)$ \\
Pessimism & $11.3 \pm 2.7$ & $11.4 \pm 2.8$ & \\
SF-36 & & & \\
Physical function & $92.1 \pm 5.6$ & $90.9 \pm 9.1$ \\
Role - physical & $67.2 \pm 5.7$ & $66.9 \pm 15.0$ & 0.476 \\
Bodily pain & $84.6 \pm 12.5$ & $81.5 \pm 22.0$ & 0.896 \\
General health & $58.1 \pm 13.0$ & $60.7 \pm 16.5$ & 0.476 \\
Vitality & $65.7 \pm 10.8$ & $67.6 \pm 18.7$ & 0.424 \\
Social function & $86.6 \pm 13.4$ & $84.8 \pm 21.7$ & 0.607 \\
Role - emotional & $65.8 \pm 6.0$ & $66.6 \pm 16.7$ & 0.623 \\
Mental health & $76.7 \pm 4.9$ & $77.2 \pm 17.6$ & 0.814
\end{tabular}

Data are presented as number (\%) or median (SD), unless otherwise stated. Row percentages may not sum to 100 owing to rounding. CSQ-8 Client Satisfaction Questionnaire-8, SF-36 MOS 36-item Short-Form Health Survey

${ }^{\text {a }}$ Significant variables

$(\mathrm{OR}=0.17 ; 95 \% \mathrm{CI}=0.079-0.379 ; p<0.001)$, lower optimism according to the LOT $(\mathrm{OR}=1.24 ; 95 \% \mathrm{CI}=1.045-$ $1.470 ; p=0.014)$, and increased serum creatinine levels in the paired recipient $(\mathrm{OR}=0.05 ; 95 \% \mathrm{CI}=0.250-1.011$; $p=0.054$ ) independently increased the odds of being in the low satisfaction group (Table 2).

\section{Discussion}

The CSQ-8 scale has been used extensively within mental health care, primarily medical care, and in a wide range of human service settings [18-20]. For example, mean reported CSQ-8 scores were 25.3 and 22.1 in patients receiving collaborative care versus usual care for depression, respectively, in primary care in the United Kingdom [18]; and mean reported CSQ-8 scores ranged from 26.5 to 27.0 among Filipino women receiving childbirth-related care [19]. These results are in line with the mean CSQ-8 score of 26.9 in the present study.

Decreased perceptions of having received adequate information prior to transplantation was one of the risk factors for lower post-donation satisfaction in this study.
Believing that information given preoperatively was inadequate has been reported to be correlated with LKD dissatisfaction [1]. Conversely, in one survey on informed consent among LKDs, donors' perceptions of understanding the effects of living donation on recipient outcomes was related to the donors' decision to donate again [25]. Furthermore, recent reviews on psychosocial issues in LKDs have suggested that post-donation feelings of being inadequately informed preoperatively were associated with HRQoL, particularly psychological well-being $[15,26]$.

Optimism has been reported as having a positive effect on psychological [13] and physical [14] aspects among LKDs, suggesting a positive effect on post-donation satisfaction. A recent large cross-sectional cohort study demonstrated that having lower self-reported optimism was one of the factors that contributed to increased depressive symptoms following kidney donation [13]. Another study demonstrated the positive influence of optimism on wound healing in LKDs [14]. Optimism has been reported to have a positive relationship with increased HRQoL in patients with several illnesses, including those undergoing

Table 2 Multiple logistic regression analysis for predictors of donor satisfaction

\begin{tabular}{|c|c|c|c|c|c|c|}
\hline & \multirow[t]{2}{*}{$B$} & \multirow[t]{2}{*}{ Wald } & \multirow[t]{2}{*}{$\operatorname{Exp}(B)$} & \multicolumn{2}{|c|}{ 95\% Cl for $\operatorname{Exp}(\mathrm{B})$} & \multirow[t]{2}{*}{$p$} \\
\hline & & & & Lower & Upper & \\
\hline \multicolumn{7}{|l|}{ Donor variables } \\
\hline $\begin{array}{l}\text { Perception of donation results and transplant procedure } \\
\text { Adequate information prior to transplant* }\end{array}$ & -1.753 & 19.258 & 0.173 & 0.079 & 0.379 & 0.000 \\
\hline Life Orientation Test Optimism & 0.215 & 6.084 & 1.240 & 1.045 & 1.470 & 0.014 \\
\hline \multicolumn{7}{|l|}{ Recipient variables } \\
\hline Serum creatinine level, current & -.687 & 3.721 & 0.503 & 0.250 & 1.011 & 0.054 \\
\hline
\end{tabular}

* Lower score indicates better perception

Cl confidence interval

We conducted the multiple (binomial) logistic regression analysis with forward stepwise variable selection to detect predictors of donor satisfaction. Six variables from univariate analyses with $p<0.1$ were included in the model. Of the six variables, the following three were excluded in forward stepwise variables selection: "increase in self-esteem/self-worth after donation" in Perception of donation results and transplant procedure, donor Self-Rating Depression Scale score, and recipient CSQ-8 score 
heart transplantation [27], as well as a positive relationship with increased mental well-being and distress among caregivers of patients with cancer [28].

Recipients' adverse outcomes may be associated with feelings of waste and guilt [1], depression, as well as conflict in the donor-recipient relationship [29]. It has been reported that LKDs whose paired recipient died within 1 year of transplantation were more likely to state that they would not donate again if repeat donation were possible [2]. Conversely, one study of living liver donors conducted in the United States demonstrated that 100\% of donors would donate again and would recommend donation to someone considering organ donation, even though $12 \%$ of recipients did not improve after transplantation [30]. In the present study, we did not include recipients with serous negative outcomes, e.g., graft loss or death. Instead, high serum creatinine levels, indicating a poor post-transplant condition in recipients, were found to be related to lower post-donation satisfaction. Poor self-care or nonadherence, which can occur in some recipients, may be associated with dissatisfaction in donors.

Chronic pain has been reported in several studies as an important factor influencing post-donation QOL and satisfaction $[9,31]$, although laparoscopic surgical procedures have contributed to reducing perioperative pain and discomfort. A recent study has demonstrated that one-quarter of donors who underwent a hand-assisted laparoscopic donor nephrectomy experienced chronic post-donation pain or discomfort, most of which was bothersome [32]. In the present study, however, pain was not associated with donors' satisfaction.

We must mention an important cultural aspect in this study. Unlike in Western countries, nearly all kidney transplantation in Japan involves living donors; for example, $89.3 \%$ of a total 1648 transplanted kidneys in 2016 were from living donors [33]. As we have mentioned, in principle, living organ donors in Japan are limited to family members. Several ethical problems directly related to such family relationships have been identified [16], and the Asian mentality around family has been the subject of debate [17]. However, such relationships with family, including understanding and support from the family, was not associated with post-donation dissatisfaction in the present study.

The strength of this study is that we successfully clarified the risk factors for low post-donation satisfaction using a valid instrument. In addition, this study may contribute to the understanding of decision-making and satisfaction among LKDs in the context of Asian family relationships.

The study does, however, have certain limitations. First, we primarily recruited recipients who were followed up in a post-transplant outpatient service, and we asked recipients if their donors would participate in this study. Therefore, recipients who left the outpatient service owing to worsened outcome (e.g., returning to hemodialysis after graft loss, or death) were not included in this study; thus, donors paired with such recipients were not included. Although we recommended that all donors undergo regular follow-up at our transplant center, this was not necessarily adhered to by all donors because the patient may have been too old to visit the clinic, they lived far away, or they were followed by their primary physician. Second, if recipients did not want their paired donor to participate in this study, these donors were excluded from this study. Third, like all such surveys, ours was subject to self-selection bias owing to the donors themselves. Indeed, it is possible that issues beyond those discussed here exist among such donors. Fourth, because this study was carried out at a single center located in metropolitan Tokyo, our findings may not be applicable to people living in other areas of Japan; for instance, nuclear families are more frequent in urban than in rural areas. Fifth, because study participants were limited to Japanese people, our findings may not be applicable to other ethnic groups. Sixth, other possible mediating factors associated with dissatisfaction were not tested, e.g., psychological traits other than depression or optimism. Finally, the number of respondents was relatively low for the identification of risk factors for low satisfaction among LKDs.

Finally, we used the CSQ-8, a standardized scale for global client/patient satisfaction with health services and clinical care, to evaluate post-donation satisfaction levels in the present study. However, donor satisfaction has been reported to be multifaceted. For example, as mentioned, Menjivar et al. [9] suggested that donor satisfaction seems better characterized according to the following three dimensions: unmet donor expectations about donation; interference of donation with daily activities, and pain and discomfort. Therefore, the methodology in donor satisfaction research should be further considered based on the results of such qualitative studies.

To overcome several of these limitations, prospective, multi-facet studies focusing on post-donation satisfaction among LKDs that use standardized tools, such as those used in this study, may be required in the future.

\section{Conclusions}

In this cross-sectional study of post-donation satisfaction among LKDs using a validated instrument, the CSQ-8, we identified three risk factors: (1) a perception of receiving inadequate prior information, (2) donor pessimism, and (3) poor post-transplant physical condition of the recipient, as indicated by high serum creatinine levels. Our findings suggest that careful pre-donation education and more detailed informed consent may be needed, especially among LKDs with low constitutional optimism. 


\section{Supplementary information}

Supplementary information accompanies this paper at https://doi.org/10. 1186/s12913-019-4556-5.

Additional file 1. Donors' perception of donation results and transplant procedure. A 13-item scale developed from a qualitative study of potential LKDs on the factors influencing decision-making when considering donation.

\section{Abbreviations}

Cl: Confidence interval; CSQ-8: Client Satisfaction Questionnaire-8; HRQoL: Health-related quality of life; LKD: Living kidney donor; LOT: Life Orientation Test; OR: Odds ratio; SD: Standard deviation; SDS: Zung SelfRating Depression Scale; SF-36: Short Form-36 Health Survey

\section{Acknowledgments}

We thank Dr. Hiroto Ito, Research Center for Overwork-Related Disorders, National Institute of Occupational Safety and Health, for his support in the use of the Japanese version of the CSQ-8. We also thank Analisa Avila, ELS, of Edanz Group (www.edanzediting.com/ac) for editing a draft of this manuscript.

\section{Authors' contributions}

SK and KN participated in the research design. SK, RA, and KN participated in the writing of the paper and data analysis. KO, HS, TS, HI, and KT participated in collecting and interpreting the data. All authors have read and approved the final manuscript.

\section{Funding}

No funding was received.

\section{Availability of data and materials}

The datasets used and/or analyzed during the current study are available from the corresponding author on reasonable request.

\section{Ethics approval and consent to participate}

This study was approved by the human ethics review board of Tokyo Women's Medical University, and all participants signed a consent form.

\section{Consent for publication}

Not applicable.

\section{Competing interests}

The authors declare that they have no competing interests.

\section{Author details}

'Department of Psychiatry, Tokyo Women's Medical University, School of Medicine, Tokyo, Japan. ${ }^{2}$ Department of Psychiatry, Saitama Medical Center, Saitama Medical University, Kawagoe, Japan. ${ }^{3}$ Department of Urology, Tokyo Women's Medical University, School of Medicine, Tokyo, Japan. ${ }^{4}$ Department of Urology, Toda Chuo General Hospital, Saitama, Japan. ${ }^{5}$ Department of Urology, Tokyo Metropolitan Health and Medical Treatment Corporation Okubo Hospital, Tokyo, Japan. ${ }^{6}$ Department of Organ Transplant Medicine, Tokyo Women's Medical University, School of Medicine, Tokyo, Japan.

Received: 2 October 2018 Accepted: 24 September 2019

Published online: 26 October 2019

\section{References}

1. Schover LR, Streem SB, Boparai N, Duriak K, Novick AC. The psychosocial impact of donating a kidney: long-term follow-up from a urology based center. J Urol. 1997:157:1596-601.

2. Johnson EM, Anderson JK, Jacobs C, et al. Long-term follow-up of living kidney donors: quality of life after donation. Transplantation. 1999:67:717-21.

3. Isotani S, Fujisawa M, Ichikawa Y, et al. Quality of life of living kidney donors: the short-form 36-item health questionnaire survey. Urology. 2002;60:588-92.

4. Giessing $M$, Reuter $S$, Schönberger B, et al. Quality of life of living kidney donors in Germany: a survey with the validated short Form-36 and Giessen subjective complaints List-24 questionnaires. Transplantation. 2004;78:864-72.
5. Reimer J, Rensing A, Haasen C, Philipp T, Pietruck F, Franke GH. The impact of living-related kidney transplantation on the donor's life. Transplantation. 2006;81:1268-73.

6. Mjøen G, Stavem K, Westlie L, et al. Quality of life in kidney donors. Am J Transplant. 2011;11:1315-9.

7. Clemens K, Boudville N, Dew MA, et al. The long-term quality of life of living kidney donors: a multicenter cohort study. Am J Transplant. 2011;11:463-9.

8. Nolan MT, Walton-Moss B, Taylor L, Dane K. Living kidney donor decision making: state of the science and directions for future research. Prog Transplant. 2004;14:201-9.

9. Menjivar A, Torres X, Paredes D, et al. Assessment of donor satisfaction as an essential part of living donor kidney transplantation: an eleven-year retrospective study. Transpl Int. 2018;31:1332-44.

10. Larsen DL, Attkisson CC, Hargreaves WA, Nguyen TD. Assessment of client/ patient satisfaction: development of a general scale. Eval Program Plann. 1979;2:197-207

11. Tachimori $\mathrm{H}$, Ito $\mathrm{H}$. Reliability and validity of the Japanese version of the client satisfaction questionnaire. Seishin Igaku Clin Psychiatry. 1999;41:711-7 [in Japanese].

12. Clemens KK, Thiessen-Philbrook H, Parikh CR, et al. Psychosocial health of living kidney donors: a systematic review. Am J Transplant. 2006:6:2965-77.

13. Jowsey SG, Jacobs C, Gross CR, et al. Emotional well-being of living kidney donors: findings from the RELIVE study. Am J Transplant. 2014:14:2535-44.

14. Maple H, Chilcot J, Lee V, Simmonds S, Weinman J, Mamode N. Stress predicts the trajectory of wound healing in living kidney donors as measured by highresolution ultrasound. Brain Behav Immun. 2015;43:19-26.

15. Dew MA, Jacobs CL. Psychosocial and socioeconomic issues facing the living kidney donor. Adv Chronic Kidney Dis. 2012;19:237-43.

16. Biller-Andorno N. Voluntariness in living-related organ donation. Transplantation. 2011;92:617-9.

17. Fujita M, Akabayashi A, Slingsby BT, Kosugi S, Fujimoto Y, Tanaka K. A mode of donors' decision-making in adult-to-adult living donor liver transplantation in Japan: having no choice. Liver Transpl. 2006;12:768-74.

18. Richards DA, Hill JJ, Gask L, et al. Clinical effectiveness of collaborative care for depression in UK primary care (CADET): cluster randomised controlled trial. BMJ. 2013:347:44913.

19. Matsubara C, Green J, Astorga LT, et al. Reliability tests and validation tests of the client satisfaction questionnaire (CSQ-8) as an index of satisfaction with childbirth-related care among Filipino women. BMC Pregnancy Childbirth. 2013;13:235. https://doi.org/10.1186/1471-2393-13-235.

20. Thyen U, Lux A, Jürgensen M, Hiort O, Köhler B. Utilization of health care services and satisfaction with care in adults affected by disorders of sex development (DSD). J Gen Intern Med. 2014;29:S752-9.

21. Fukuhara S, Ware JE Jr, Kosinski M, Wada S, Gandek B. Psychometric and clinical tests of validity of the Japanese SF-36 health survey. J Clin Epidemiol. 1998;51:1045-53.

22. Zung WWK. A self-rating depression scale. Arch Gen Psychiatry. 1965;12:63-70.

23. Scheier MF, Carver CS. Optimism, coping, and health: assessment and implications of generalized outcome expectancies. Health Psychol. 1985;4:219-47.

24. Kobayashi S, Akaho R, Omoto K, et al. Development of the donors' perception scale for the donation results and transplant procedure in livingkidney transplantation in Japan. Submitted. [In Japanese].

25. Valapour M, Kahn JP, Bailey RF, Matas AJ. Assessing elements of informed consent among living donors. Clin Transpl. 2011;25:185-90.

26. Schroder NM, McDonald LA, Etringer G, Snyders M. Consideration of psychosocial factors in the evaluation of living donors. Prog Transplant. 2008;18:41-8.

27. Milaniak I, Wilczek-Rużyczka E, Przybyłowski P, Wierzbicki K, Siwińska J, Sadowski J. Psychological predictors (personal recourses) of quality of life for heart transplant recipients. Transplant Proc. 2014:46:2839-43.

28. Butow PN, Price MA, Bell ML, et al. Caring for women with ovarian cancer in the last year of life: a longitudinal study of caregiver quality of life, distress and unmet needs. Gynecol Oncol. 2014;132:690-7

29. Fisher PA, Kropp DJ, Fleming EA. Impact on living kidney donors: quality of life, self-image and family dynamics. Nephrol Nurs J. 2005;32:489-501.

30. Beavers KL, Sandler RS, Fair JH, Johnson MW, Shrestha R. The living donor experience: donor health assessment and outcomes after living donor liver transplantation. Liver Transpl. 2001:7:943-7.

31. Smith GC, Trauer T, Kerr PG, Chadban SJ. Prospective psychosocial monitoring of living kidney donors using the short Form-36 health survey: results at 12 months. Transplantation. 2004;78:1384-9. 
32. Zorgdrager $M$, van Londen $M$, Westenberg $L B$, et al. Chronic pain after hand-assisted laparoscopic donor nephrectomy. Br J Surg. 2019;106:711-9.

33. The Japan Society for Transplantation. FACTBOOK 2017. http://www. asas.or.jp/jst/pdf/factbook/factbook2017.pdf. Accessed August 19, 2018. [In Japanese].

\section{Publisher's Note}

Springer Nature remains neutral with regard to jurisdictional claims in published maps and institutional affiliations.

Ready to submit your research? Choose BMC and benefit from:

- fast, convenient online submission

- thorough peer review by experienced researchers in your field

- rapid publication on acceptance

- support for research data, including large and complex data types

- gold Open Access which fosters wider collaboration and increased citations

- maximum visibility for your research: over $100 \mathrm{M}$ website views per year

At $B M C$, research is always in progress.

Learn more biomedcentral.com/submissions 